\title{
Familial autonomic visceral myopathy with degeneration of muscularis mucosae
}

\author{
E M ALSTEAD, ${ }^{*}$ M N MURPHY,$\dagger$ A M FLANAGAN, $\dagger$ A E BISHOP,$\ddagger$ \\ H J F HODGSON* \\ From the Departments of *Medicine, $\nmid$ Histopathology, and $\ddagger$ Histochemistry, Royal Postgraduate Medical \\ School, Hammersmith Hospital, London
}

SUMMARY An extended family with chronic intestinal pseudo-obstruction which affected 11 of 54 members was studied. Patients presented with recurrent intestinal obstruction in childhood or adolescence: eight of the 11 died before the age of 30. Pedigree analysis showed four consanguineous marriages. The patients were all in the fifth generation and had established an autosomal recessive mode of inheritance. Histological, immunocytochemical, and electron microscopic studies were performed on a colectomy specimen from a surviving affected family member. Familial visceral myopathy was diagnosed-characterised by degeneration and collagenous replacement of both layers of the muscularis propria and the muscularis mucosae.

Chronic intestinal pseudo-obstruction is a clinical syndrome caused by ineffective intestinal propulsion and is characterised by recurrent or chronic symptoms of small or large bowel obstruction or both, which occur in the absence of organic luminal obstruction. ${ }^{\prime}$ Both primary and secondary forms are well known. It may occur secondary to systemic diseases affecting the intestinal smooth muscle or myenteric plexus such as diabetes mellitus, systemic sclerosis, secondary amyloidosis or Chagas' disease. Some of these disorders such as amyloidosis, myxoedema, diabetes mellitus, jejunal diverticulosis and Chagas' disease have characteristic biochemical, radiological, and histological abnormalities.'

Chronic primary or idiopathic pseudo-obstruction defines a heterogenous group where there is no other evidence of a generalised underlying disorder. Cases have been described where pseudo-obstruction resulted from degeneration of the myenteric plexus, ${ }^{2-4}$ or degeneration of the intestinal smooth muscle (muscularis propria)..$^{5-8}$ Other cases have been described where no histological abnormality was shown ${ }^{9-13}$ but motor abnormalities were found on physiological testing. The coexistence of smooth muscle and neuronal abnormalities has recently been described. ${ }^{14}$

The patient reported here is a member of an intermarried kindred in whom visceral myopathy seems to have been inherited as an autosomal recessive.

Accepted for publication 14 October 1987

\section{Case report}

The family studied comprised 54 members of a kindred descended from a single pair of great great grandparents, and included four consanguineous marriages. Of the 28 members of the fifth generation of this kindred, 11 were affected by bowel symptoms including abdominal pain, diarrhoea, and intermittent episodes of intestinal obstruction. Eight died following multiple abdominal operations (fig 1).

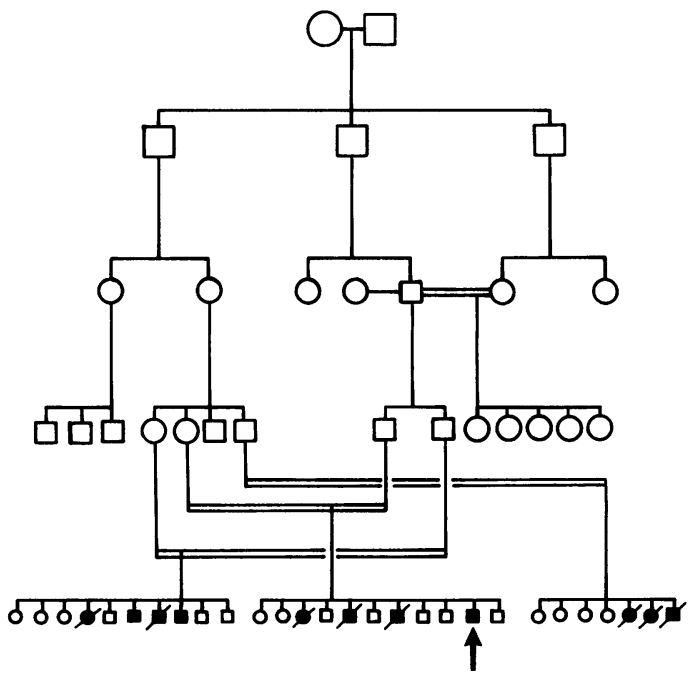

Fig 1 Kindred diagram showing affected family members in black. 
Further investigation of the family history showed that two brothers died in their 20 s. One died aged 28 , having had four laporotomies for abdominal pain, vomiting, and diarrhoea. Late in the course of his illness he had an abnormal electromyogram, but this may have been related to his general debility rather than to a specific skeletal muscle myopathy. The other brother died aged 26 with a history of abdominal pain, distension, and diarrhoea with six episodes of intestinal obstructions and laparotomies. He had no neurological abnormalities. A sister had also died at the age of 16 following acute abdominal symptoms.

An 18 year old male sibling was alive but had had two years of colicky abdominal pain and constipation. He had undergone a colectomy and ileorectal anastomosis because of intractible constipation, and the colectomy specimen was subsequently available for histological examination.

Three female and two male cousins of this branch of the family also died following multiple laparotomies for intestinal obstruction in Iraq. They also had histories of abdominal pain, distension, and diarrhoea.

Two male cousins are affected but are still alive at the time of writing. A male cousin now aged 28 has intermittent episodes of diarrhoea and vomiting, abdominal pain, and distension. He is weak and wasted but has had some response to treatment with pyridostigmine and rotating courses of antibiotics. A further male cousin in his $20 \mathrm{~s}$ is similarly affected.

Barium radiology in these subjects showed pronounced dilatation of the colon with loss of haustral markings. Some of the affected family members also had pronounced distension of the duodenum and small bowel. There was no evidence on barium radiological examination of oesophageal aperistalsis. Manometry was not performed.

\section{Histological examination}

\section{CONVENTIONAL LIGHT MICROSCOPY}

A surgical specimen of $20 \mathrm{~cm}$ of colon with $2 \mathrm{~cm}$ of terminal ileum was examined. The colon was grossly dilated with a slightly hyperaemic mucosa. Sections of the bowel wall were cut in longitudinal and cross sectional planes, fixed in buffered $10 \%$ formalin, processed in paraffin, and 3-5 $\mu \mathrm{m}$ sections were stained with haematoxylin and eosin, Masson's trichrome, Congo red, and Verhoeff's van Gieson.

Enzyme histochemical analysis for acetylcholinesterase was performed on fresh tissue by the direct thiocholine method modified after Karnovsky and Roots. $^{15}$

IMMUNOCYTOCHEMICAL ANALYSIS

Fresh colonic tissue was fixed in benzoquinone solu- tion $(0.4 \% \mathrm{w} / \mathrm{v}$ in $0.01 \mathrm{M}$ phosphate buffered $0.15 \mathrm{M}$ saline, ph 7.4) for two hours and rinsed overnight in $15 \%$ sucrose $(\mathrm{w} / \mathrm{v})$ and $0.1 \%$ sodium azide $(\mathrm{w} / \mathrm{v})$ in phosphate buffered saline. ${ }^{16}$ Cryostat sections were prepared and $10 \mu \mathrm{m}$ transverse sections cut and collected on poly-L-lysine coated glass slides ${ }^{17}$ and air dried for 30 minutes at room temperature. For immunocytochemical analysis, an indirect immunofluorescence technique was applied. Sections were incubated with appropriately diluted antisera for 16 hours at $4^{\circ} \mathrm{C}$ in a moist atmosphere. After several rinses in phosphate buffered saline (PBS) a second layer of fluorescein isocyanate-conjugated goat antirabbit 1 gG (Miles Scientific Laboratories, dilution 1 in 200) was applied and left to incubate for one hour at room temperature. After washing in PBS the sections were mounted in an aqueous medium (PBS:glycerine, 1:9) and observed under a Leitz 2-orthoplan microscope equipped with an ultraviolet source. Controls for the specificity of the immunostains were carried out, including the omission of first antisera $\mathrm{ur}$ the use of non-immune serum as first layer. Where possible, preabsorption of the primary antisera was done using the corresponding antigen.

\section{ELECTRON MICROSCOPICAL ANALYSIS}

Cubed pieces of fresh tissue $(1 \mathrm{~mm})$ were fixed in $3 \%$ phosphate buffered glutaraldehyde for one to two hours at $4^{\circ} \mathrm{C}$. The pieces were washed in phosphate buffer and fixed in $1 \%$ buffered osmium tetroxide for one hour at $4^{\circ} \mathrm{C}$. After rinsing in distilled water, the specimen was dehydrated in 2,2 dimethoxypropane (twice for 15 minutes) embedded in resin TAAB and polymerised at $60^{\circ} \mathrm{C}$ for 16 to 24 hours. Sections $(1 \mu \mathrm{m})$ were cut, stained with $1 \%$ toluidine blue in $1 \%$ borax, and viewed under a light microscope to select an area for thin sectioning. Appropriate blocks were cut with a diamond knife and placed on grids, stained with uranyl acetate methanolic for two minutes, washed in distilled water and counterstained with Reynold's lead citrate for 15 minutes. Sections were viewed with an AEI 801 electron microscope.

\section{Results}

\section{LIGHT MICROSCOPY}

Examination of the colon showed an intact mucosa with a mild increase in the round cell population within the lamina propria. The submucosa was normal, with no excessive fibrosis, inflammatory infiltrate, or amyloid deposition. Vessels and submucosal ganglion cells were normal. There were striking changes in the muscularis propria, affecting both the external and internal muscle layers, and the muscularis mucosae. There was patchy muscle fibre degeneration (fig 2) with secondary replacement by collagen. This 


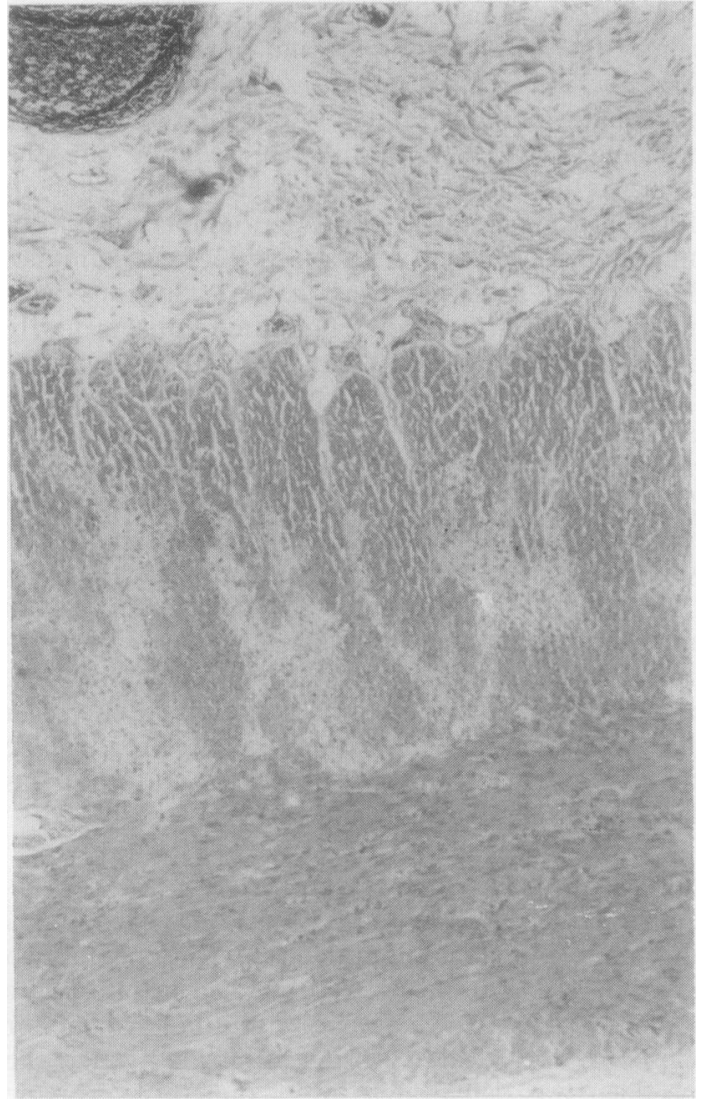

Fig 2 This section shows degeneration of muscularis propria, affecting especially inner muscle layer (Haematoxylin and eosin).

degeneration was characterised by fibre size variation, increased cytoplasmic eosinophilia, degenerate and pyknotic nuclei, and provacuolation (fig 3). Masson's stain showed a diffuse fibrosis with collagen replacing lost muscle fibres and surrounding fibres changed in structure. The ganglion cells of the myenteric plexus were normal in number and morphology. The specimens also showed degeneration of smooth muscle fibres with collagen deposition and fat replacement (fig 4) affecting the muscularis mucosae.

\section{ENZYME HISTOCHEMISTRY}

Ganglion cells and nerves positive for acetylcholinesterase were noted in normal numbers within the submucosa and muscularis propria. The numbers of fibres were not excessive within the lamina propria.

\section{IMMUNOCYTOCHEMISTRY}

With antisera to the general neuronal markers (nuronespecific enclosed, neutrophils, PGPB, GFAP,

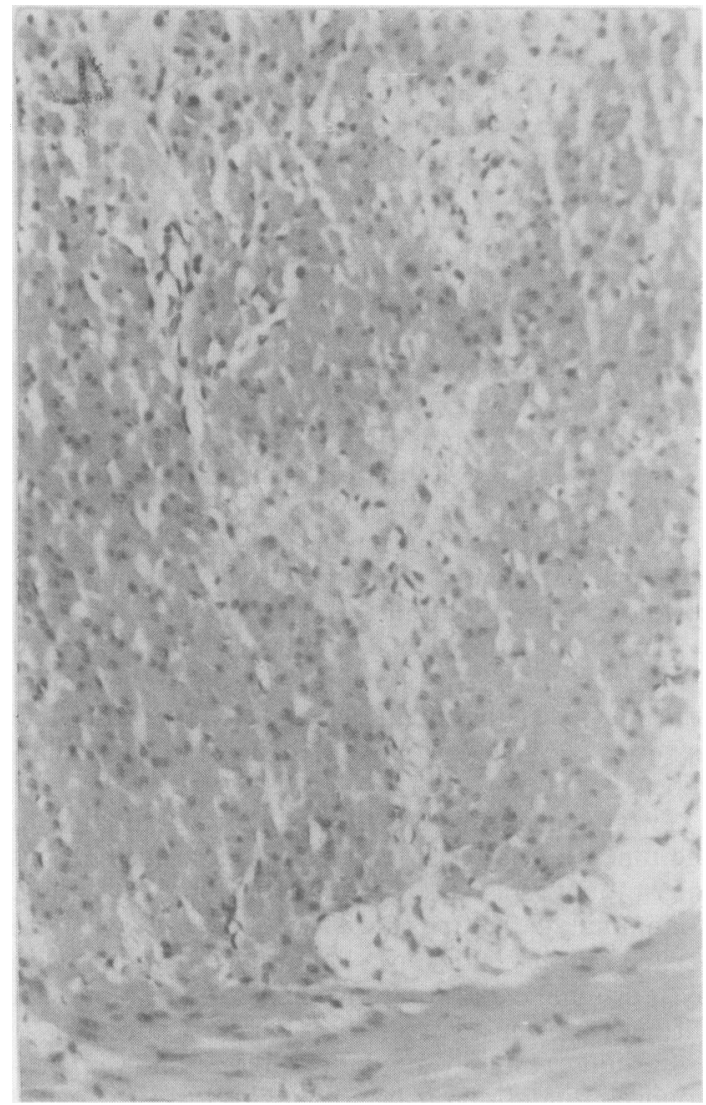

Fig 3 Muscularis propria, featuring muscle fibre loss with collagen replacement, vacuolation of some muscle fibres and degenerative muscle changes. Note intact nerve plexus in bottom right hand corner. (Haematoxylin and eosin).

S-100), neuronal cell bodies with a normal morphology were found in both of the ganglionated plexuses. The number of cell bodies and the density of nerve fibres were comparable with those of the normal bowel. Fibres within the muscle layers and mucosa showed no obvious abnormality, apart from some increase in nerve bundles along the inner edge of the circular muscle in some areas. The various intrinsic and extrinsic peptide containing nerves showed no abnormality in terms of either number of individual morphology. Antibodies to chromogranin showed a reduction in the population of endocrine cells in the normal epithelium. The specific cell types affected seemed to be those containing glucagon, PYY, and somatostatin. Serotonin producing enterochromaffin cells were present in normal numbers.

ELECTRON MICROSCOPY

Examination showed normal smooth muscle cells, 


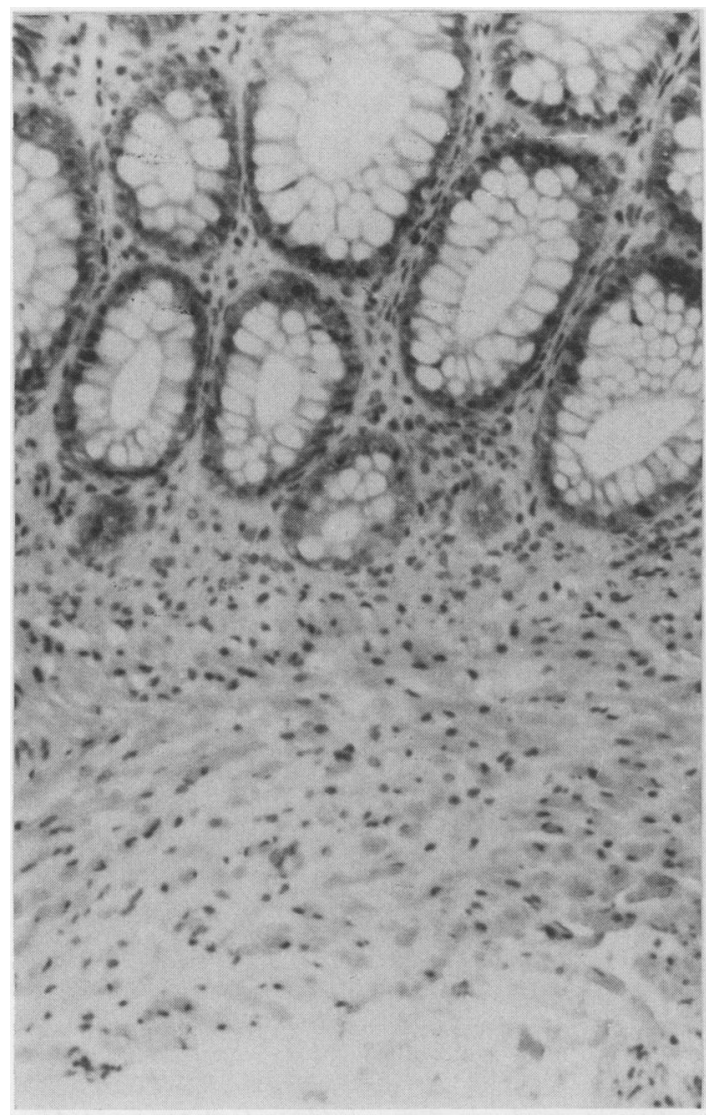

Fig 4 Muscularis mucosae showing some degenerative changes of muscle fibres-namely, vacuolation and pyknotic nuclei. (Haematoxylin and eosin).

alternating with muscle fibres exhibiting extensive damage within the muscularis propria and muscularis mucosae. The damaged smooth muscle fibres were characterised by disrupted and disorientated intracytoplasmic myofilaments, loss of myofilaments, and increased radiolucency of the cytoplasm, especially at the periphery of the cell (fig 5). Affected muscle cells varied in size and were separated from each other by varying amounts of extracellular collagen fibres. In contrast to the muscle cells, the myenteric plexus and nerve fibres were normal.

\section{Discussion}

The clinical and pathological findings in this family are characteristic of familial visceral myopathy. The incidence in 11 members of the same generation of the blood relations suggests an autosomal recessive inheritance. The previously reported histological hallmark of familial visceral myopathy has been the degeneration of the muscularis propria. The patient also had degenerative changes in the muscularis mucosae, a feature not previously described.

Previous reports have described two distinct types of familial visceral myopathy. These are either inherited as an autosomal dominant ${ }^{41018-21}$ or autosomal recessive. ${ }^{11222-26}$ The seven families described with the autosomal dominant form tended to have more localised gastrointestinal abnormalities, oesophageal aperistalsis, megaduodenum and megacolon, and in some families this was associated with megacystis and uterine inertia. The symptoms in these subjects were variable and there were asymptomatic affected family members. ${ }^{9}$ Familial visceral myopathy tends to run a relapsing and remitting course but has a good prognosis. The vitosomal dominant and recessive forms are histologically indistinguishable.

Four families have been described with a recessively inherited form of visceral myopathy. ${ }^{11222} 23$ There was more extensive small and large bowel disease in these patients. They had severe abdominal symptoms, vomiting, pain, distension and, most commonly, diarrhoea and commonly underwent many laparotomies for intestinal obstruction, often dying following complications of one of these procedures. The course of these patients generally was more rapidly downhill, although there may be periods of months to years free of incapacitating symptoms. Some families with a recessive form of familial visceral myopathy have been reported to have external ophthalmoplegia ${ }^{22}$ and one family was reported as having a skeletal myopathy. ${ }^{23}$ Other families did not have extragastrointestinal manifestations ${ }^{12}$ as in the family reported here.

The usual histological findings in familial visceral myopathy are smooth muscle degeneration of the muscularis propria, with the external longitudinal layer more affected than the internal circular fibres. The submucosal ganglion cells and myenteric plexus are described as being normal. ${ }^{13}$ The muscularis mucosae has been found to be normal in previous reports. ${ }^{113}$

This study extends the previously reported findings in autosomal recessively inherited visceral myopathy in two ways. Firstly, in this family the histological abnormalities extended to the muscularis mucosae. Secondly, the phenotypic abnormality seems to be confined to the gastrointestinal smooth muscle, although present throughout the thickness of the gastrointestinal wall. The immunohistochemical studies reported here support the findings from conventional staining of neurones and ganglion cells that the allele is expressed primarily in the muscle. We have not identified a loss of any one of a number of recently recognised neurotransmitters that might lead to muscle degeneration. 


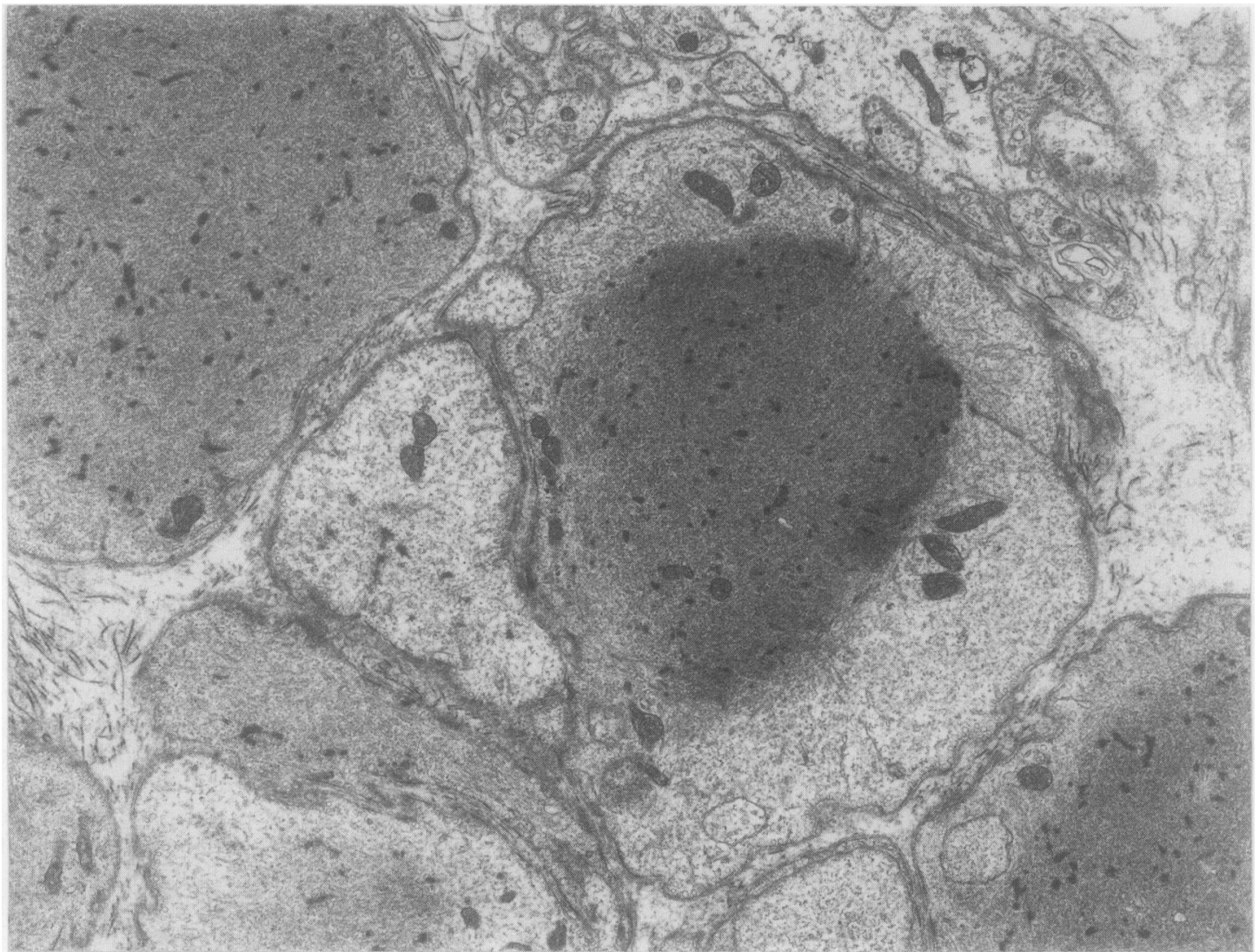

Fig 5 Note diminished number of myofilaments with radiolucency of periphery of smooth muscle fibres. Collagen is noted in extracellular spaces.

\section{References}

1 Schuffler MD, Rohrman CA, Chaffee RG, Brand DC, Delaney JH, Young JH. Chronic intestinal pseudoobstruction. A report of 27 cases and review of the literature. Medicine 1981;60: 173-96.

2 Maldonado JE, Gregg JA, Green PA, Brown AL. Chronic idiopathic intestinal pseudoobstruction. Am $J$ Med 1970;49:203-12.

3 Sullivan MA, Snape WJ, Matarazzo AS, Petrokubi RJ, Jeffries G, Cohen S. Gastrointestinal myoelectrical activity in idiopathic intestinal pseudoobstruction. N Engl J Med 1977;297:233-8.

4 Lewis TD, Daniel EE, Sarna SK, Waterfall WE, Marzio L. Idiopathic intestinal pseudoobstruction. Report of a case with intraluminal studies of mechanical and electrical activity, and response to drugs. Gastroenterology 1978;74:107-11.

5 Dyer NH, Dawson AM, Smith BF, Todd IP, Obstruction of bowel due to lesion in the myenteric plexus. Br Med J 1969;1:686-9.

6 Schuffler MD, Bird TD, Sumi SM, Cook A. A familial neuronal disease presenting as intestinal pseudoobstruction. Gastroenterology 1978;75:889-8.

7 Schuffler MD, Jonak Z. Chronic idiopathic intestinal pseudoobstruction caused by degenerative disorder of the myenteric plexus: the use of Smith's method to define the neuropathy. Gastroenterology 1982;82:476-86.

8 Cockel R, Hill EE, Rushton DL, Smith B, Hawkins CF. Familial steatorrhoea with calcification of the basal ganglia and mental retardation. $Q J$ Med 1973;42:771-83.

9 Schuffler MD, Pope CE. Studies of idiopathic intestinal pseudoobstruction. I. Hereditary hollow visceral myopathy: clinical and pathological studies. Gastroenterology 1977;73:327-38.

10 Faulk DL, Anuras S, Gardner GD, Mitros FA, Summers RW, Christerisen J. A familial visceral myopathy. Ann Intern Med 1978;89:600-6.

11 Jacobs E, Ardichvili D, Perissino A, Gollignies P, Hanssens JF. A case of familial visceral myopathy with atrophy and fibrosis of the longitudinal muscle layer of the entire small bowel. Gastroenterology 1979;77:745-50.

12 Anuras S, Mitros FA, Milano A, Kuminsky R, Decanio R, Green JB. A familial visceral myopathy with dilatation of the entire gastrointestinal tract. Gastroenterology 1986;90:385-90.

13 Mitros FA, Schuffler MD, Teja K, Anuras S. Pathologic features of familial visceral myopathy. Hum Pathol 1982:13:825-33.

14 Smout AJPM, de Wilde K, Kooyman CD, Ten Thije OJ. Chronic idiopathic intestinal pseudoobstruction. Coexistance of smooth muscle and neuronal abnormalities. Dig Dis Sci 1985;30:282-7.

15 Karnovsky MJ, Roots L. A "direct coloring" thiocholine method for choline esterase. J Histochem Cytochem 1964;12:219-21.

16 Bishop AE, Polak JM, Bloom SR, Pearse AGE. A new universal technique for the immunocytochemical localisation of peptidergic innervation. J Endcrinol 1978;77:25-6.

17 Huang WM, Gibson SJ, Facer P, Gu J, Polak JM. Improved 
section adhesion for immunocytochemistry using high molecular weight polymers of L-lysine as a slide coating. Histochemistry 1983;77:275-9.

18 Shaw A, Shaffer H, Teja K, Kelly T, Grogan E, Bruni C. A perspective for paediatric surgeons. Chronic idiopathic intestinal pseudoobstruction. J Paediatr Surg 1979;14:719-27.

19 Weiss W. Zur atiologie des Megaduodenums. Deutsche Zeitschrift für Chirugie 1938;251:317-30.

20 Law DH, Ten Eyck EA. Familial megaduodenum and magacystis. AM J Med 1961;33:991-1022.

21 Newton WT. Radical enterectomy for hereditary megaduodenum. Archives of Surgery 1968;96:549-53.

22 Anuras S, Mitros FA, Nowak TV, et al. A familial visceral myopathy with external ophthalmoplegia and autosomal recessive transmission. Gastroenterology 1983;84:346-53.

23 Ionasescu VV, Thompson HS, Aschenbrener C, Anuras S. Late onset oculogastrointestinal muscular dystrophy. Am J Med Genet 1984;18:781-8.

24 Schuffler MD. Chronic intestinal pseudo-obstruction syndromes. Med Clin North Am 1985;65:1331-58.

25 Warner E, Jeejeebhoy KN. Successful management of chronic intestinal pseudoobstruction with home parenteral nutrition. JPEN 1985;9:173-8.

26 Shaw A, Shaffer HA, Anuras S. Familial visceral myopathy: the role of surgery. Am J Surg 1985;150:102-8.

Requests for reprints to: Dr A M Flanagan, Clinical Lecturer, Department of Histopathology, St George's Hospital Medical School, Cranmer Terrace, Tooting, London SW17 0RE, England. 